\title{
Sol-Gel Synthesis of a Nanostructured Hybrid Material from an Organosiloxane Oligomer with a Terminal Phenyl Group
}

\author{
Atsushi SHIMOJIMA, ${ }^{*, * *}$ Norimasa ATSUMI, ${ }^{* * *}$ Noritaka UMEDA, ${ }^{* * *}$ \\ Yasuhiro FUJIMOTO ${ }^{* * *}$ and Kazuyuki KURODA*,**,*** \\ *Core Research for Evolutional Science and Technology (CREST), Japan Science and Technology Agency (JST), Japan \\ **Kagami Memorial Laboratory for Materials Science and Technology, Waseda University, \\ 2-8-26, Nishiwaseda, Shinjuku-ku, Tokyo 169-0051 \\ ***Department of Applied Chemistry, Waseda University, 3-1-1, Ohkubo, Shinjuku-ku, Tokyo 169-8555
}

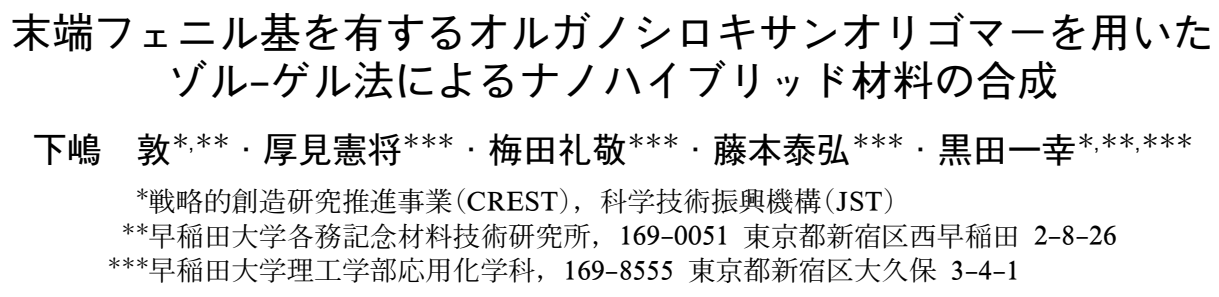

\begin{abstract}
A novel ordered siloxane-organic hybrid material has been prepared by hydrolysis and polycondensation of a well-defined alkoxysilane precursor consisting of a tetrasiloxane unit and a 4-phenylbutyl group (1). Evaporation-induced self-assembly during hydrolysis and polycondensation of 1 led to the formation of a twodimensional (2D) hexagonal mesostructure, which was revealed by $\mathrm{X}$-ray diffraction (XRD) and transmission electron microscopy (TEM). Solid-state ${ }^{13} \mathrm{C}$ CP/MAS NMR and ${ }^{29}$ Si MAS NMR confirmed that the product consisted of 4-phenylbutyl groups and siloxane networks, both of which are linked via Si-C bonds. These results will allow us to produce functional hybrid materials by chemical modification of phenyl groups, and also by incorporating other organic groups. Furthermore, calcination of this hybrid to remove organic groups led to the creation of an ordered microporous silica with the Brunauer-Emmett-Teller (BET) surface area of $570 \mathrm{~m}^{2} \mathrm{~g}^{-1}$ and the average pore diameter of $1.2 \mathrm{~nm}$.

[Received June 27, 2006; Accepted August 24, 2006]
\end{abstract}

Key-words : Organoalkoxysilane, Sol-gel processing, Self-assembly, Silica-based hybrid, Microporous silica

\section{Introduction}

Inorganic-organic hybrid materials have attracted growing interests because of the possibility of combining the properties of both inorganic and organic components. The sol-gel process using organoalkoxysilanes $\left(\mathrm{R}_{n} \mathrm{Si}\left(\mathrm{OR}^{\prime}\right)_{4-n}\right)$ is a convenient method to produce silica-based hybrids, called organically-modified ceramics, where organic groups are covalently attached to siloxane networks. ${ }^{1-3)}$ While a wide variety of hybrid materials have been prepared by the molecular design of the alkoxysilane precursors, more and more research efforts have recently been directed to the control of hybrid structures at the nanometer length scale.

The use of surfactants as structure directing agents is a wellestablished pathway that enables the formation of lamellar, hexagonal, or cubic mesostructures. ${ }^{4)-6)}$ Another interesting approach is the self-directed assembly of certain organoalkoxysilanes during hydrolysis and polycondensation, providing a one-step, surfactant-free pathway to hybrid mesostructures. ${ }^{7-10)}$ We have reported the formation of multilayered hybrids from alkyltrialkoxysilanes by exploiting the amphiphilic nature of hydrolyzed species. $\left.{ }^{8}\right)$ Organically-bridged bis-alkoxysilanes with the general formula of $\left(\mathrm{R}^{\prime} \mathrm{O}\right)_{3} \mathrm{Si}-\mathrm{R}-\mathrm{Si}$ $\left(\mathrm{OR}^{\prime}\right)_{3}$ have also been used to produce lamellar hybrids, ${ }^{10)}$ which is based on the weak interactions $(\pi-\pi$ interactions, hydrogen bonding, etc.) between bridging $\mathrm{R}$ groups.

Although most of the hybrids obtained by the self-directed assembly processes have lamellar structures, we have recently succeeded in the formation of $2 \mathrm{D}$ hexagonal structures by using newly designed oligomeric precursors bearing alkyl chains
$\left(\mathrm{C}_{n} \mathrm{H}_{2 n+1} \mathrm{Si}\left(\mathrm{OSi}(\mathrm{OMe})_{3}\right)_{3}\right.$, hereafter denoted as "alkylsiloxane oligomer"). ${ }^{9)}$ The larger head group area of oligomeric head group compared to that of a single $-\mathrm{Si}(\mathrm{OH})_{3}$ group favored the formation of mesophase with a higher surface curvature. ${ }^{11)}$ In this system, incorporation of other organic groups instead of alkyl chains is very important to modify the properties of the resulting hybrids as well as to further understand the molecular factor affecting the self-assembly process.

In this paper, we report the synthesis of a novel ordered hybrid with a 2D hexagonal structure from an oligosiloxane precursor containing a terminal phenyl group (Scheme 1). The product has a unique mesostructure where "rigid" phenyl groups are integrated within the rod-like assemblies via "flexible" alkylene spacers. Furthermore, the hybrid could be converted into microporous silica by calcination. Being different

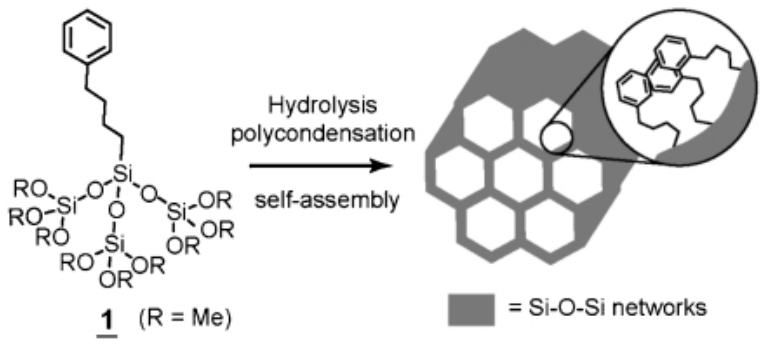

Scheme 1. Formation of a $2 \mathrm{D}$ hexagonal hybrid from the precursor (1) consisting of a tetrasiloxane unit and a 4-phenylbutyl group. 
from relatively inert alkyl chains, phenyl groups are expected to be useful for future chemical modifications, such as sulfonation and amination, to functionalize resulting hybrid materials. This result is also important as the first step to create a wide range of hybrid materials by incorporating various functional organic groups.

\section{Experimental}

2.1 Synthesis of the precursor (tris (trimethoxysilyloxy)4-phenylbutylsilane (1))

Chloroplatinic acid $\left(\mathrm{H}_{2} \mathrm{PtCl}_{6} \cdot 6 \mathrm{H}_{2} \mathrm{O}\right.$, Kanto Chemical $)$ dissolved in acetonitorile $(0.2 \mathrm{M})$ was added to a $1: 1$ (molar ratio) mixture of trichlorosilane ( $\mathrm{HSiCl}_{3}$, Tokyo Kasei Co.) and 4-phenyl-1-butene (Tokyo Kasei Co.). The mixture was stirred at $70^{\circ} \mathrm{C}$ for $2 \mathrm{~h}$ under $\mathrm{N}_{2}$ atmosphere, giving 4-phenylbutyltrichlorosilane. Controlled hydrolysis of 4-phenylbutyltrichlorosilane gave 4-phenylbutylsilanetriol, which was then reacted with an excess of tetrachlorosilane. The detailed procedure is similar to that for alkylsiloxane oligomers reported previously. ${ }^{9)}$ After the removal of the solvents and unreacted $\mathrm{SiCl}_{4}$, methanolysis of $\mathrm{Si}-\mathrm{Cl}$ groups was performed by addition of methanol. Vacuum distillation of the oily residue afforded 1 as clear and colorless liquid. Spectroscopic data for 1: ${ }^{1} \mathrm{H}$ NMR $\left(500 \mathrm{MHz}, \mathrm{CDCl}_{3}\right): \delta(\mathrm{ppm}) 0.76-0.80(t, 2 \mathrm{H}$; $\left.\mathrm{SiCH}_{2}\right), 1.50-1.58(m, 2 \mathrm{H}), 1.66-1.74(m, 2 \mathrm{H}), 2.61-2.64$ $(t, 2 \mathrm{H}), 3.56\left(s, 27 \mathrm{H} ; \mathrm{OCH}_{3}\right), 7.12-7.18(m, 3 \mathrm{H}), 7.23-7.26$ $(t, 2 \mathrm{H}) ;{ }^{13} \mathrm{C}$ NMR $\left(125.7 \mathrm{MHz}, \mathrm{CDCl}_{3}\right): \delta$ (ppm) 12.89, $22.41,34.78,35.72,51.03,125.65,128.28,128.47,142.64 ;{ }^{29} \mathrm{Si}$ NMR $\left(99.3 \mathrm{MHz}, \mathrm{CDCl}_{3}\right): \delta(\mathrm{ppm})-67.23\left(\mathrm{~T}^{3}\right),-86.38$ $\left(\mathrm{Q}^{1}\right)$. HRMS (FAB): $m / z(\%): 541.3(100)\left[\mathrm{M}-\mathrm{OCH}_{3}{ }^{+}\right]$.

\subsection{Synthesis of silica-based hybrids}

Hydrolysis and polycondensation of $\mathbf{1}$ was performed in the solution with a molar ratio of $\mathbf{1} /$ tetrahydrofuran $(\mathrm{THF}) /$ $\mathrm{H}_{2} \mathrm{O} / \mathrm{HCl}=1: 50: 18: 0.002$. After $12 \mathrm{~h}$ of stirring at $25^{\circ} \mathrm{C}$, water $\left(\mathrm{H}_{2} \mathrm{O} / \mathbf{1}=32\right)$ was added. This precursor solution was cast on glass substrates, and air-dried at room temperature for 2 days. The resulting thick film was pulverized for characterization. A thin film was also prepared by spin-coating on glass substrate (Corning \#7059) at room temperature and under relative humidity of $40-45 \%$. For comparison, co-hydrolysis and polycondensation of 4-phenylbutyltrimethoxysilane (2) and TMOS was performed with the molar ratio of $2 /$ TMOS/ $\mathrm{THF} / \mathrm{H}_{2} \mathrm{O} / \mathrm{HCl}=1: 3: 30: 15: 0.002$ under otherwise identical conditions.

\subsection{Characterization}

The XRD patterns of the hybrid (powder and film) were obtained on a Mac Science M03XHF22 diffractometer with $\mathrm{Mn}$-filtered $\mathrm{Fe} \mathrm{K} \alpha$ radiation. The TEM images were obtained on JEOL JEM-2010 microscope operated at $200 \mathrm{kV}$. Solidstate ${ }^{29} \mathrm{Si}$ MAS NMR spectra of the powdered samples were recorded on a JEOL JNM-CMX-400 spectrometer at a resonance frequency of $79.42 \mathrm{MHz}$, with a pulse width of $45^{\circ}$, and a recycle delay of $100 \mathrm{~s}$. Solid-state ${ }^{13} \mathrm{C} \mathrm{CP} / \mathrm{MAS}$ NMR spectrum was recorded on the same spectrometer at a resonance frequency of $100.54 \mathrm{MHz}$ and a recycle delay of $5 \mathrm{~s}$. The liquid-state ${ }^{29} \mathrm{Si}$ NMR spectra of the precursor solutions were obtained on a JEOL Lambda-500 spectrometer with a resonance frequency of $99.25 \mathrm{MHz} \cdot .^{9)}$ A nitrogen adsorptiondesorption measurement of the calcined sample was performed by an Autosorb-1 instrument (Quantachrome Instruments, Inc) at $77 \mathrm{~K}$. The sample was preheated at $120{ }^{\circ} \mathrm{C}$ for $3 \mathrm{~h}$ under 1.3 Pa Torr. The BET surface area was calculated from the adsorption data in the relative pressure range from 0.02 to 0.05 . The pore size distribution was evaluated using the non-local density functional theory (NLDFT). ${ }^{12)}$

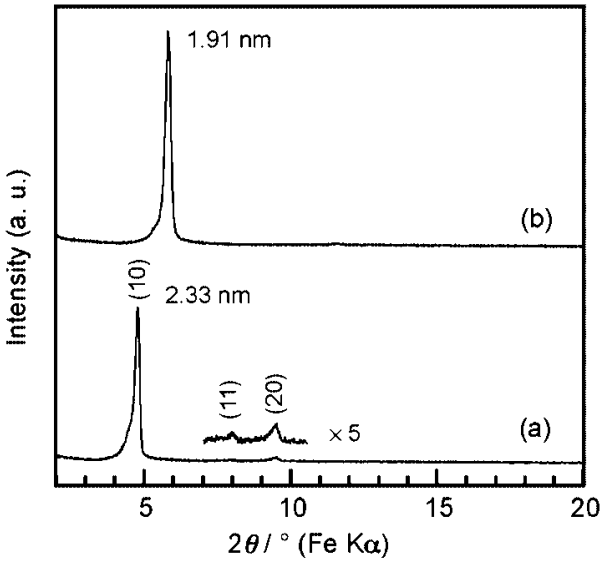

Fig. 1. Powder XRD patterns of the hybrids derived from 1: (a) assynthesized and (b) calcined $\left(500^{\circ} \mathrm{C}\right.$ for $\left.8 \mathrm{~h}\right)$.
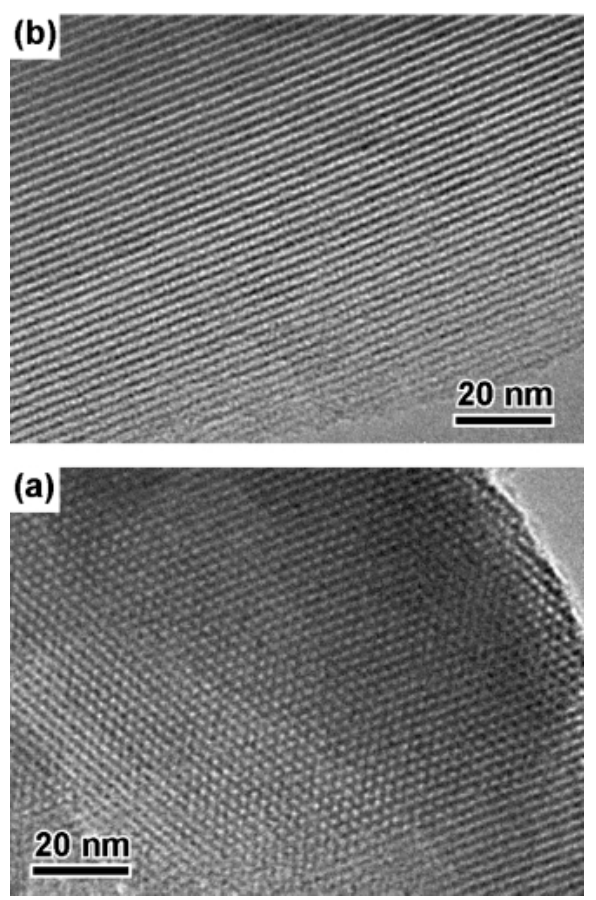

Fig. 2. TEM images of the hybrid (powder) derived from 1. Views (a) parallel and (b) perpendicular to the long axis of the cylindrical assembly.

\section{Results and discussion}

The thick film obtained by casting the precursor solution of 1 was a birefringent solid. The XRD pattern of the powdered sample (Fig. 1(a)) shows the strongest peak at the $d$-spacing of $2.33 \mathrm{~nm}$ and two small peaks at higher $2 \theta$ region. These peaks can be attributed to the 10,11 , and 20 reflections of a 2D hexagonal mesostructure. Actually, the 2D hexagonal structure of this sample was confirmed by TEM (Fig. 2). Both hexagonally ordered patterns and striped patterns are observable, depending on the direction of electron incidence either parallel or perpendicular to the long-axis of the rod-like assembly.

The ${ }^{29} \mathrm{Si}$ MAS NMR spectrum of the hybrid (Fig. 3(a)) shows the signals corresponding to the $\mathrm{T}^{1}, \mathrm{~T}^{2}$, and $\mathrm{T}^{3}$ units $\left(\mathrm{T}^{x}, \mathrm{CSi}(\mathrm{OSi})_{x}(\mathrm{OH})_{3-x}\right)$, and to the $\mathrm{Q}^{2}, \mathrm{Q}^{3}$, and $\mathrm{Q}^{4}$ units $\left(\mathrm{Q}^{x}, \mathrm{Si}(\mathrm{OSi})_{x}(\mathrm{OH})_{4-x}\right)$, indicating the formation of the 


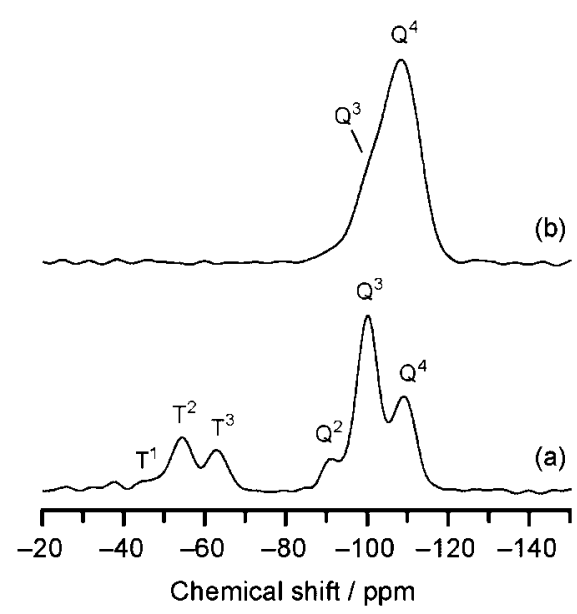

Fig. 3. ${ }^{29} \mathrm{Si}$ MAS NMR spectra of the hybrid (powder) derived from 1: (a) as-synthesized and (b) calcined.

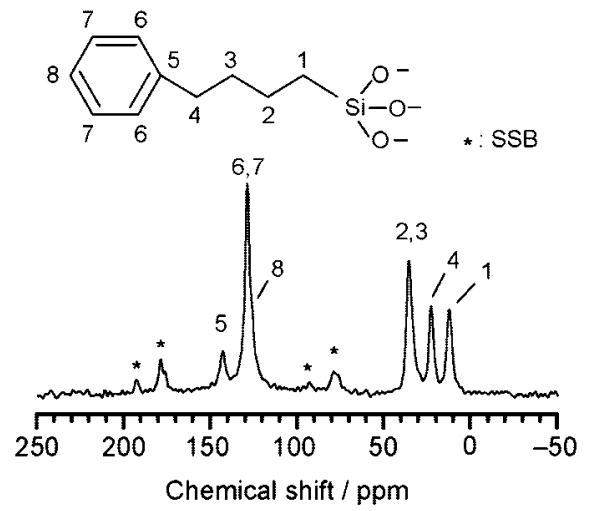

Fig. 4. ${ }^{13} \mathrm{C} \mathrm{CP} / \mathrm{MAS}$ NMR spectrum of the as-synthesized hybrid (powder) derived from 1.

siloxane networks. The presence of the $\mathrm{T}^{1}$ and $\mathrm{T}^{2}$ units suggests the partial cleavage and the rearrangement of the $\mathrm{Si}-\mathrm{O}$ $\mathrm{Si}$ bonds in the precursor $\mathbf{1}$ during hydrolysis and polycondensation, as we reported for alkylsiloxane oligomers. ${ }^{9)}$ The ${ }^{13} \mathrm{C}$ CP/MAS NMR spectrum (Fig. 4) only shows the signals due to 4-phenylbutyl groups. No signal was detected at around 50 ppm, confirming complete hydrolysis of methoxy groups of $\mathbf{1}$.

A transparent thin film with a thickness of ca. $450 \mathrm{~nm}$ was obtained by spin-coating the precursor solution on a glass substrate. Figure 5 shows the XRD pattern of the film. A sharp peak at $d=2.21 \mathrm{~nm}$, along with its second and third order reflections, are observed. The TEM image of the crosssection of this film (Fig. 6) revealed the 2D-hexagonal mesostructure where rod-like assemblies are mostly oriented parallel to the substrate. This is consistent with the absence of a (11) peak in the XRD pattern. ${ }^{13)}$ The smaller $d_{10}$-spacing for the film compared to the powdered sample (Fig. 1(a)) is due to the anisotropic shrinkage of the hexagonal lattice along the direction normal to the film surface, which is also evident from the TEM image.

The mesostructure of the powdered hybrid was retained after calcination at $500^{\circ} \mathrm{C}$ for $8 \mathrm{~h}$, although the $d_{10}$-spacing decreased to $1.91 \mathrm{~nm}$ (Fig. 1(b)). The hybrid film after calcination showed a much smaller $d_{10}$-spacing $(1.36 \mathrm{~nm})$, which should be due to further anisotropic shrinkage of the siloxane networks. The ${ }^{29} \mathrm{Si}$ NMR spectrum of the calcined powders

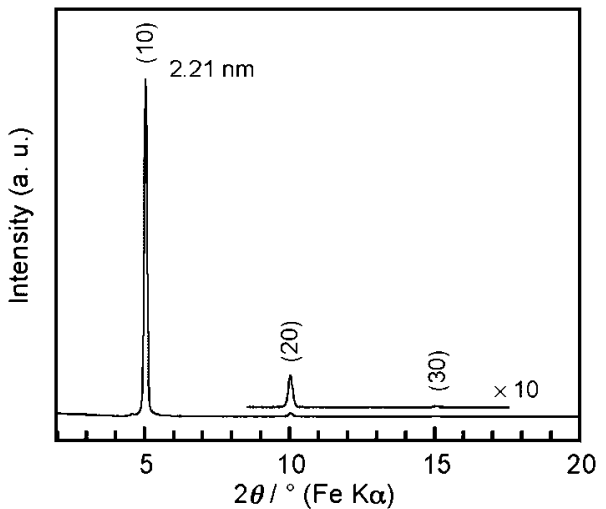

Fig. 5. XRD pattern of the thin film of the hybrid derived from $\mathbf{1}$.
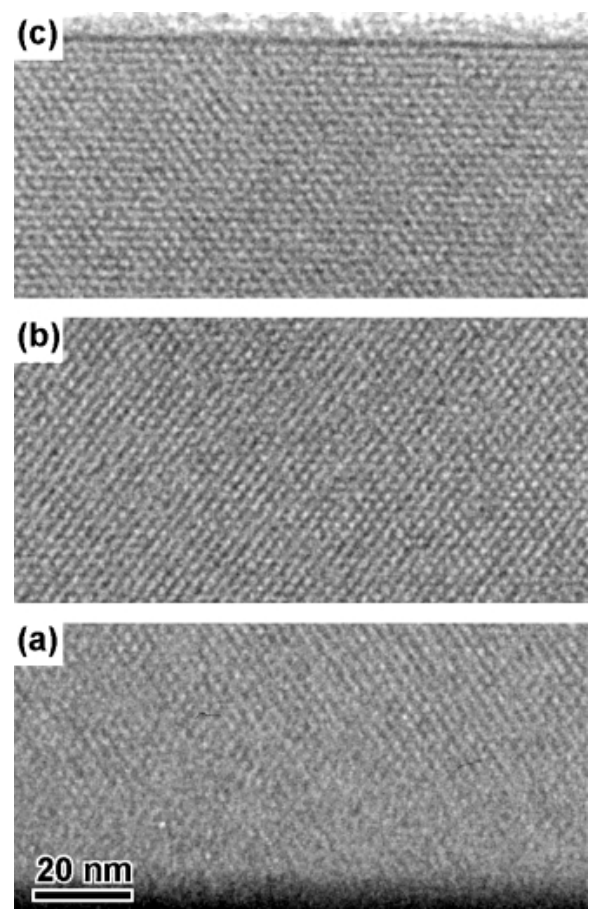

Fig. 6. TEM images of the cross-section of the hybrid film derived from 1: (a) region adjacent to the substrate, (b) central region, and (c) region adjacent to the film surface.

showed only $\mathrm{Q}^{3}$ and $\mathrm{Q}^{4}$ signals (Fig. 3(b)), suggesting the conversion of the $T$ units to the $Q$ units by thermal cleavage of $\mathrm{Si}-\mathrm{C}$ bonds.

Although the as-synthesized hybrid was non-porous, ordered micropores were generated by combustion of the organic groups. The nitrogen adsorption isotherm of the calcined sample (Fig. 7) displays a type I curve, typically observed for microporous silica. The BET surface area of $570 \mathrm{~m}^{2}$ $\mathrm{g}^{-1}$, the average NLDFT pore diameter of $1.2 \mathrm{~nm}$, and the pore volume of $0.26 \mathrm{~cm}^{3} \mathrm{~g}^{-1}$ were evaluated. These values are close to those for the microporous silica prepared using an alkylsiloxane oligomer with a hexyl (C6) chain. ${ }^{9)}$ From the pore diameter and the $d_{10}$ value $(1.91 \mathrm{~nm})$ of the calcined sample, the thickness of the siloxane wall is calculated to be ca. 1.0 nm.

The possible structural model of the mesostructured hybrid is illustrated in Scheme 1. The $d_{10}$ value of the 1-derived hybrid $(2.33 \mathrm{~nm})$ is intermediate between those of the hybrids der- 


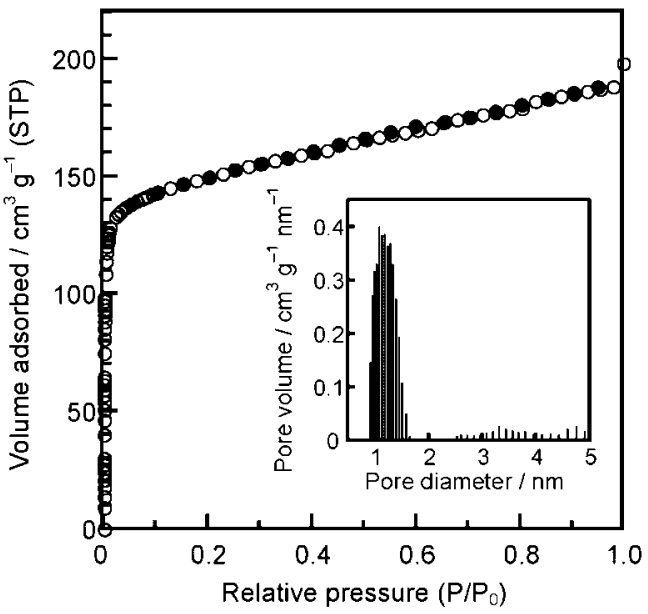

Fig. 7. Nitrogen adsorption-desorption isotherms for the calcined hybrid (powder) derived from 1. Open symbols and filled symbols denote adsorption and desorption, respectively. The inset shows the NLDFT pore size distribution histogram.

ived from the alkylsiloxane oligomers with C6 and octyl (C8) chains (2.13 and $2.52 \mathrm{~nm}$, respectively).$^{9)}$ This is consistent with the fact that the extended length of the 4-phenylbutyl group (ca. $0.9 \mathrm{~nm}$ ) is intermediate between those of C6 and $\mathrm{C} 8$ chains. It is plausible that phenyl groups are not stacked at the center of the rod-like assembly, because the molecular modeling suggests that the lateral distance between the siloxane head groups at the surface of a rod becomes too large to form cylindrical siloxane networks. From the variation in the $d_{10}$-spacings before and after calcination, the thickness of the siloxane wall before thermal shrinkage is estimated to be ca. $1.2 \mathrm{~nm}$. Then the diameter of the rod-like assembly of phenylbutyl groups is calculated to be $1.5 \mathrm{~nm}$. Because this value is smaller than twice the extended length of 4phenylbutyl group (ca. $1.9 \mathrm{~nm}$ ), the butylene spacers may adopt mixed trans-gauche conformations.

The formation of such a mesostructure relies on the selfassembly of amphiphilic oligomeric species upon evaporation of the solvents, followed by polycondensation to form siloxane networks. This is the first example of the selfassembly of organosilane molecules having an aromatic organic part into a $2 \mathrm{D}$ hexagonal structure. It appears that the alkylene spacer, $-\left(\mathrm{CH}_{2}\right)_{4^{-}}$, plays a crucial role in the present self-assembly processes. We note here that an oligomeric precursor with a 2-phenylethyl group, having a shorter alkylene spacer, produced a poorly ordered hybrid that exhibited a weak, broad XRD peak at around $d=2.1 \mathrm{~nm}$ (data not shown). It should also be noted that the alkylsiloxane oligomer with a butyl group did not afford a well-ordered hybrid as well, ${ }^{9)}$ possibly due to the low hydrophobic nature of butyl group. Thus the terminal phenyl group of $\mathbf{1}$ acts as a part of the hydrophobic tail to induce self-assembly.

Such a 2D hexagonal mesostructure could not be obtained by co-condensation of monomeric alkoxysilanes, a $1: 3 \mathrm{mix}-$ ture of 4-phenylbutyltrimethoxysilane (2) and TMOS, suggesting the importance of the well-designed molecular structure of $\mathbf{1}$. The hybrid prepared from the 2-TMOS system exhibited a single diffraction peak at $\boldsymbol{d}=2.92 \mathrm{~nm}(2.70 \mathrm{~nm}$ for a thin film) (data not shown). The lamellar structure of this hybrid was confirmed by the disappearance of the XRD peak upon calcination. Such a difference is apparently due to the difference in the distribution of oligomeric species in the precursor solutions, as described below. The precursor solution prepared from 1 mainly showed three signals at the $\mathrm{T}^{2}(-57.1$ ppm) and $\mathrm{Q}^{2}(-89.9$ and $-90.0 \mathrm{ppm})$ regions with the intensity ratio of $1: 2: 1$. These signals are assigned to a cyclic tetrasiloxane unit, as we reported for the alkylsiloxane oligomers. $^{9)}$ In contrast, the precursor solution of the 2-TMOS system exhibited many signals at $T^{0}, T^{1}, T^{2}, Q^{1}, Q^{2}$, and $\mathrm{Q}^{3}$ regions, suggesting the presence of a relatively broad distribution of oligomeric species. The presence of $\mathrm{T}^{0}$ units indicates very slow condensation rate of $\mathrm{T}$ units, arising from the steric hindrance of bulky phenylbutyl groups. Thus the precursor solution in the 2-TMOS system consists of the species with relatively smaller head group areas, which should be responsible for the formation of a lamellar phase rather than a 2D hexagonal phase. ${ }^{11)}$

\section{Conclusion}

In conclusion, we have demonstrated the successful formation of a novel silica-based hybrid with a well-ordered 2Dhexagonal structure from an organosiloxane oligomer containing a terminal phenyl group. In addition to chemical modification of the phenyl groups, an interesting extension of this phenyl-functionalized hybrid is its conversion into carbon-silica hybrid composites. Furthermore, the present result promises the formation of a broad range of ordered hybrid materials by incorporating various organic functional groups such as polymerizable groups (pyrrol, thiophene, etc.) and organic chromophores instead of simple alkyl chains.

Acknowledgements This work was supported in part by a Grant-in-Aid for COE Research "Molecular Nano-Engineering," the 21st Century COE Program "Practical Nano-Chemistry," and Encouraging Development Strategic Research Centers Program "Establishment of Consolidated Research Institute for Advanced Science and Medical Care" from MEXT, Japan. The A3 Foresight Program "Synthesis and Structural Resolution of Novel Mesoporous Materials" supported by the Japan Society for Promotion of Science (JSPS) is also acknowledged.

\section{References}

1) Novak, B. M., Adv. Mater., Vol. 5, pp. 422-433 (1993)

2) Wen, J. and Wilkes, G. L., Chem. Mater., Vol. 8, pp. 1667-1681 (1996).

3) Corriu, R. J. P. and Leclercq, D., Angew. Chem., Int. Ed. Engl., Vol. 35, pp. 1421-1436 (1996).

4) Soler-Illia, G. J. de A. A., Sanchez, C., Lebeau, B. and Patarin, J., Chem. Rev., Vol. 102, pp. 4093-4138 (2002).

5) Nicole, L., Boissiere, C., Grosso, D., Alida, Q. and Sanchez, C., J. Mater. Chem., Vol. 15, pp. 3598-3627 (2005).

6) Hoffmann, F., Cornelius, M., Morell, J. and Fröba, M., Angew. Chem. Int. Ed., Vol. 45, pp. 3216-3251 (2006).

7) Katagiri, K., Ariga, K. and Kikuchi, J., Chem. Lett., pp. 661-662 (1999).

8) Shimojima, A. and Kuroda, K., Chem. Rec., Vol. 6, pp. 53-63 (2006).

9) Shimojima, A., Liu, Z., Ohsuna, T., Terasaki, O. and Kuroda, K., J. Am. Chem. Soc., Vol. 127, pp. 14108-14116 (2005).

10) Boury, B. and Corriu, R., Chem. Rec., Vol. 3, pp. 120-132 (2003).

11) Israelachvili, J. N., Mitchell, D. J. and Ninham, B. W., J. Chem. Soc., Faraday Trans. II, Vol. 72, pp. 1525-1568 (1976).

12) Ravikovitch, P. I., Wei, D., Chueh, W. T., Haller, G. L. and Neimark, A. V., J. Phys. Chem. B, Vol. 101, pp. 3671-3679 (1997).

13) Hillhouse, H. W., van Egmond, J. W., Tsapatsis, M., Hanson, J. C. and Larese, J. Z., Microporous Mesoporous Mater., Vol. 44-45, pp. 639-643 (2001). 